\title{
Serum Albumin Concentration and Heart Failure Risk:
}

\author{
The Health, Aging, and Body Composition Study
}

Deepa Gopal, MD1, Andreas P. Kalogeropoulos, MD², Vasiliki V. Georgiopoulou, MD2, Wilson W.H. Tang, MD ${ }^{3}$, Amanda Methvin ${ }^{2}$, Andrew L. Smith, MD ${ }^{2}$, Douglas C. Bauer, MD ${ }^{4}$, Anne B. Newman, MD MPH ${ }^{5}$, Lauren Kim, MD $^{6}$, Tamara B. Harris, MD MS ${ }^{6}$, Stephen B. Kritchevsky, $\mathrm{PhD}^{7}$, and Javed Butler, MD MPH${ }^{2}$ for the Health ABC Study

${ }^{1}$ Boston University, Boston, MA

${ }^{2}$ Emory University, Atlanta, GA

${ }^{3}$ Cleveland Clinic Foundation, Cleveland, $\mathrm{OH}$

${ }^{4}$ University of California San Francisco, San Francisco, CA

${ }^{5}$ University of Pittsburgh, Pittsburgh, PA

${ }^{6}$ Intramural Research Program, National Institute of Aging, National Institutes of Health, Bethesda, MD

${ }^{7}$ Sticht Center on Aging, Wake Forest University, Winston Salem, NC

\section{Abstract}

Background-How serum albumin levels are associated with risk for heart failure (HF) in the elderly is unclear.

Methods-We evaluated 2907 participants without HF (age, $73.6 \pm 2.9$ years; $48.0 \%$ male; $58.7 \%$ white) from the community-based Health ABC Study. The association between baseline albumin and incident $\mathrm{HF}$ was assessed with standard and competing-risks proportional hazards models controlling for HF predictors, inflammatory markers, and incident coronary events.

Results-During a median follow-up of 9.4 years, 342 (11.8\%) participants developed HF. Albumin was a time-dependent predictor of HF, with significance retained for up to 6 years (baseline HR per -1g/L, 1.14; 95\% CI, 1.06-1.22; $\mathrm{P}<0.001$; annual rate of HR decline, $2.1 \%$; $95 \%$ CI, $0.8-3.3 \%$; $\mathrm{P}=0.001)$. This association persisted in models controlling for HF predictors, inflammatory markers, and incident coronary events (baseline HR per - $1 \mathrm{~g} / \mathrm{L}, 1.13$; $95 \%$ CI, $1.05-$ 1.22; $\mathrm{P}=0.001$; annual rate of HR decline, $1.8 \% ; 95 \% \mathrm{CI}, 0.5-3.0 \% ; \mathrm{P}=0.008)$ and when mortality was accounted for in adjusted competing risks models (baseline HR per $-1 \mathrm{~g} / \mathrm{L}, 1.13 ; 95 \% \mathrm{CI}$, $1.05-1.21 ; \mathrm{P}=0.001 ;$ annual rate of $\mathrm{HR}$ decline, $1.9 \% ; 95 \% \mathrm{CI}, 0.7-3.1 \% ; \mathrm{P}=0.002)$. The association of albumin with HF risk was similar in men (HR per -1g/L, 1.13; 95\% CI, 1.05-1.23; $\mathrm{P}=0.002)$ and women $(\mathrm{HR}$ per $-1 \mathrm{~g} / \mathrm{L}, 1.12 ; 95 \% \mathrm{CI}, 1.04-1.22 ; \mathrm{P}=0.005)$ and in whites and blacks (HR per $-1 \mathrm{~g} / \mathrm{L}, 1.13 ; 95 \% \mathrm{CI}, 1.04-1.22 ; \mathrm{P}<0.01$ for both races) in adjusted models.

(C) 2010 Mosby, Inc. All rights reserved.

Address correspondence to: Javed Butler, MD MPH, Emory University Hospital, 1365 Clifton Road NE, Suite AT430, Atlanta, GA 30322. Telephone: 404-778-5273, Fax: 404-778-5285, javed.butler@emory.edu.

Publisher's Disclaimer: This is a PDF file of an unedited manuscript that has been accepted for publication. As a service to our customers we are providing this early version of the manuscript. The manuscript will undergo copyediting, typesetting, and review of the resulting proof before it is published in its final citable form. Please note that during the production process errors may be discovered which could affect the content, and all legal disclaimers that apply to the journal pertain. 
Conclusions-Low serum albumin levels are associated with increased risk for HF in the elderly in a time-dependent manner independent of inflammation and incident coronary events.

\section{Keywords}

Serum Albumin; Heart Failure; Epidemiology; Elderly

Several prospective studies have demonstrated an association between low serum albumin and increased cardiovascular morbidity and mortality. $1^{-} 4$ A reduction in serum albumin over time is associated with increased incidence of cardiovascular disease, even if the change is within normal albumin range. ${ }^{5}$ In patients with established heart failure (HF), hypoalbuminemia is associated with 1- and 5-year all-cause mortality, HF-related mortality, and need for heart transplantation. ${ }^{6}$ Whether this association is independent of other risk factors is not well established. We have recently shown that, among the elderly, albumin concentrations were independently associated with 5-year risk for HF.7Low serum albumin concentrations may be associated with HF for several reasons. Hypoalbuminemia may be a marker of comorbidity burden. 8 Low serum albumin may be a reflection of inflammatory burden predisposing to HF. $9^{-12}$ Irrespective of the mechanism, considering that measurement of serum albumin is relatively inexpensive and widely available, it could serve as a potential screening tool to identify individuals at risk for HF. However, in order for serum albumin to be used as a screening tool, the generalizability and robustness of association between serum albumin and HF risk needs to be demonstrated across race and sex-based subgroups. Finally, it is unclear whether the value of albumin for determination of $\mathrm{HF}$ risk is retained when information on inflammatory markers is available or whether the increased risk is exclusively mediated by interim coronary events.

In this study, we extend our earlier findings on the association between serum albumin concentrations and risk for incident $\mathrm{HF}$ among the elderly participants of the Health $\mathrm{ABC}$ Study. Using 10-year follow-up data, we report on the form and time course of this association, explore the impact of inflammation and interim coronary events, assess the effect of the competing risk of death on the albumin-HF link, provide stratified analyses for major demographic groups, and assess for differential association of albumin with HF with reduced or preserved left ventricular ejection fraction.

\section{METHODS}

\section{Study Population}

The Health Aging Body Composition Study is a population-based cohort of 3,075 wellfunctioning, community-dwelling men and women aged 70-79 years at inception. Participants were identified from black and white residents using Medicare beneficiary rolls and residing in zip codes from the metropolitan areas of Pittsburgh, PA and Memphis, TN. The recruitment period was from March 1997 to July 1998. Eligibility criteria included: age 70-79 years at inception, no difficulties performing basic activities of daily living, selfreport of no difficulty walking one-quarter of a mile or climbing 10 steps without resting, no reported use of a cane, walker, crutches, or other equipment for movement, no history of active treatment for cancer in the previous three years, and no intention to move out of the area in the upcoming three years. The participant was excluded if participating in a trial involving a lifestyle intervention. The Institutional Review Boards at both sites approved the protocol.

Participants with HF, possible HF, or missing data on HF were excluded $(n=140)$ from this analysis. Of the 2935 participants without prevalent HF, 2908 had albumin levels at 
baseline. One participant was excluded because of an extreme outlier albumin level. The remaining 2907 participants were included in this analysis.

\section{Serum Albumin, Biochemistry, and Cytokine Measurements}

Blood samples were obtained after an overnight fast and frozen at $-70^{\circ} \mathrm{C}$ at the University of Vermont. Standard chemistries were measured by a colorimetric technique on a Johnson \& Johnson Vitros 950 analyzer. Cytokines (Interleukin-6 [IL-6], tumor necrosis factor $\alpha$ $[\mathrm{TNF}-\alpha]$, and $\mathrm{C}$-reactive protein [CRP]) were measured in duplicate by an ELISA kit from R\&D Systems. The detectable limit for IL-6 was $0.10 \mathrm{pg} / \mathrm{mL}$ and $0.18 \mathrm{pg} / \mathrm{mL}$ for TNF- $\alpha$. Serum CRP was also measured in duplicate by ELISA on the basis of purified protein and polyclonal anti-CRP antibodies. The CRP assay was standardized according to World Health Organization First International Reference Standard with a sensitivity of $0.08 \mathrm{mg} / \mathrm{L}$. The lower detection limit for CRP was $0.007 \mathrm{mg} / \mathrm{L}$. Blind duplicate analyses $(\mathrm{n}=150)$ for IL-6, CRP, and TNF- $\alpha$ showed interassay coefficients of variation of $10.3 \%, 8.0 \%$, and $15.8 \%$, respectively.

\section{Study Definitions}

Race was self-defined by the participant. Diabetes mellitus was defined as a self-reported history or use of anti-hyperglycemic medication. Smoking was defined as current, past ( $\geq$ 100 lifetime cigarettes), or never. Left ventricular hypertrophy was diagnosed from the electrocardiogram using the following criteria: $R$ amplitude $>26 \mathrm{~mm}$ in either $\mathrm{V}_{5}$ or $\mathrm{V}_{6}$, or $\mathrm{R}$ amplitude $>20 \mathrm{~mm}$ in any of leads I, II, III, aVF, or R amplitude $>12 \mathrm{~mm}$ in lead aVL or $\mathrm{R}$ amplitude in $\mathrm{V}_{5}$ or $\mathrm{V}_{6}$ plus $\mathrm{S}$ amplitude in $\mathrm{V}_{1}>35 \mathrm{~mm}$. Coronary heart disease was defined as: (1) history of surgical or percutaneous revascularization; or (2) electrocardiographic evidence of myocardial infarction; or (3) self-reported history of myocardial infarction or angina accompanied by use of anti-anginal medications. Hypertension was defined as self-reported history of physician diagnosis accompanied by use of antihypertensive medications. Incident coronary heart disease was defined as hospitalization for myocardial infarction or angina pectoris, or elective surgical or coronary revascularization.

\section{Study Outcome}

All participants were asked to report any hospitalizations, and every 6 months they were asked direct questions regarding interim events. Medical records for overnight hospitalizations were examined. All first admissions with an overnight stay that was confirmed as related to HF, based on symptoms, signs, chest radiograph results, and echocardiographic findings, using criteria similar to those used in the Cardiovascular Health Study. ${ }^{13}$ The criteria required at least HF diagnosis by a physician and treatment for HF. ${ }^{14}$ All deaths were reviewed by the Health ABC Diagnosis and Disease Ascertainment Committee and underlying causes of death were determined by central adjudication. Information on ejection fraction post-HF development was abstracted from the hospital medical records during the index hospitalization and was derived from echocardiography or left ventriculography reports.

\section{Statistical Analysis}

Descriptive statistics are presented as mean (standard deviation) for continuous and percentages for categorical variables. Differences in baseline characteristics between participants who did or did not develop incident HF were assessed with nonparametric rank sum test for continuous and Fisher's exact test for categorical variables. The correlations between comorbidities, HF risk predictors, and inflammatory markers with baseline albumin level were evaluated by Spearman rank correlation. The relation between albumin and HF 
risk was examined with a Cox proportional hazards model; proportionality of hazards was examined by including an interaction term of albumin with time. The functional form of albumin as a continuous variable was determined by examining fractional polynomial and spline transformations. ${ }^{15} \mathrm{We}$ also evaluated albumin as a categorical variable using the cohort median $(<40 \mathrm{~g} / \mathrm{L}$ vs. $\geq 40 \mathrm{~g} / \mathrm{L})$ to construct Kaplan-Meier curves and demonstrate timedependent effects.

In multivariable Cox models, we first controlled for independent clinical predictors of incident HF as previously identified. ${ }^{7}$ Secondly, as the relation of albumin and cardiovascular risk has been previously attributed to inflammation, the next set of variables included IL-6, TNF- $\alpha$, and CRP concentrations. Lastly, the impact of incident coronary events on the relationship of albumin and incident HF was included as a time-varying covariate. The proportional hazards assumption was evaluated by examining log-log survival plots and evaluation of interactions with time in extended-Cox models. Because of higher mortality in elderly and death potentially masking development of HF, we repeated the regression analyses entering death as a competing event using the extension of the Cox model as proposed by Fine and Grey. ${ }^{16}$

To examine the association of albumin on risk for HF with impaired or preserved ejection fraction (defined using a cut-off point 40\%) we performed separate regression analyses taking only HF events of the type of interest into account and censoring the other type of HF event. To compare albumin coefficients for HF with impaired vs. preserved ejection fraction we used a $z$ test where the standard error for the difference of coefficients was calculated as:

$$
S E_{\Delta}=\sqrt{S E_{1}^{1}+S E_{2}^{2}}
$$

where $S E_{1}$ and $S E_{2}$ the standard errors for the albumin coefficient in the models for HF with impaired and preserved ejection fraction, respectively.

A two-sided $\mathrm{p}<0.05$ was accepted as statistically significant. Analyses were performed with SAS 9.2 (SAS Institute Inc., Cary, NC) and STATA 10 (StataCorp, College Station, TX).

\section{Sources of funding}

This research was supported in part by the Intramural Research Program of the National Institutes of Health, National Institute on Aging, Bethesda, MD and by grants N01AG-6-2101, N01-AG-6-2103, and N01-AG-6-2106. Partial funding was also supplied via an Emory University Heart and Vascular Board grant entitled 'Novel Risk Markers and Prognosis Determination in Heart Failure'. The authors are solely responsible for the study design and conduct, all study analyses, drafting and editing of the paper, and its final contents.

\section{RESULTS}

\section{Baseline Participant Characteristics}

The mean age of participants was $73.6 \pm 2.9$ years with $48.0 \%$ male and $58.7 \%$ white. Mean albumin was $39.8 \mathrm{~g} / \mathrm{L}$ (range 28.0 to 50.0). Median follow-up was 9.4 years (interquartile range, 7.0-9.4 years). During this period, 342 of 2907 (11.8\%) participants developed HF (incidence rate of $14.9,95 \% \mathrm{CI}, 13.4-16.5$ per 1000 person-years). Table 1 presents the baseline characteristics of participants. Baseline inflammatory markers (IL-6, TNF- $\alpha$, and CRP) were higher in participants who developed HF. Data on post-HF ejection fraction were 
available for 265 of $342(77.5 \%)$ cases. Among these, $129(48.7 \%)$ had impaired $(\leq 40 \%)$ whereas $136(51.3 \%)$ had relatively preserved ejection fraction $(>40 \%)$.

\section{Serum Albumin and Heart Failure Risk}

In univariate Cox models, there was a linear, time-dependent association between baseline serum albumin concentrations and HF risk (Table 2, Figure 1A). Lower serum albumin was associated with an increased risk for up to 6 years, in a diminishing rate; the risk was not statistically significant thereafter. The baseline HR for $1 \mathrm{~g} / \mathrm{L}$ lower serum albumin was 1.14 (95\% CI, 1.06-1.22; P<0.001) and declined with an annual rate of $2.1 \%$ (95\% CI, $0.8-3.3 \%$; $\mathrm{P}=0.001$ ), Table 2 . This association persisted in nested models controlling for HF predictors, inflammatory markers, and incident coronary events (baseline HR per $-1 \mathrm{~g} / \mathrm{L}, 1.13 ; 95 \% \mathrm{CI}$, 1.05-1.22; $\mathrm{P}=0.001$; annual rate of $\mathrm{HR}$ decline, $1.8 \% ; 95 \% \mathrm{CI}, 0.5-3.0 \% ; \mathrm{P}=0.008$ ) (Figure 1B-1D). When the competing risk of death was accounted for in competing risks models, the estimates were not materially altered; in the fully adjusted model, the baseline HR for $1 \mathrm{~g} / \mathrm{L}$ lower serum albumin was $1.13(95 \% \mathrm{CI}, 1.05-1.21 ; \mathrm{P}=0.001)$ and declined with an annual rate of $1.9 \%$ (95\% CI, $0.7-3.1 \% ; \mathrm{P}=0.002)$. Figure 2 presents the Kaplan-Meier rates of incident $\mathrm{HF}$ among participants with serum albumin concentrations $<40 \mathrm{~g} / \mathrm{L}$ vs. $\geq 40 \mathrm{~g} / \mathrm{L}$ (cohort median). Baseline serum albumin concentrations according to incident HF status over time are presented in Table 3; the relationship persisted for the first 7 years of followup; difference became non-significant thereafter.

\section{Subgroup Analyses}

The association of serum albumin and incident HF was similar in men and women (baseline HR per $-1 \mathrm{~g} / \mathrm{L}$ in the fully adjusted model, $1.13 ; 95 \% \mathrm{CI}, 1.05-1.23 ; \mathrm{P}=0.002$ and $1.12 ; 95 \%$ CI, 1.04-1.22; $\mathrm{P}=0.005$ for men and women, respectively; $\mathrm{P}=0.82$ for the interaction term) (Table 4). Similarly, the association was consistent in whites and blacks (baseline HR per $-1 \mathrm{~g} / \mathrm{L}$ in the fully adjusted model, $1.13 ; 95 \% \mathrm{CI}, 1.04-1.22 ; \mathrm{P}=0.004$ and $1.13 ; 95 \% \mathrm{CI}$, 1.04-1.22; $\mathrm{P}=0.003$ for whites and blacks, respectively; $\mathrm{P}=0.97$ for the interaction term).

When only cases with impaired ejection fraction were considered $(n=129)$, albumin was not associated with incident $\mathrm{HF}$ risk in univariate (HR per $-1 \mathrm{~g} / \mathrm{L}, 1.08$; 95\% CI, 0.96-1.21; $\mathrm{P}=0.19$; annual rate of $\mathrm{HR}$ decline, $1.3 \% ; 95 \% \mathrm{CI},-0.09$ to $3.5 \% ; \mathrm{P}=0.23$ ) or multivariate models (HR per $-1 \mathrm{~g} / \mathrm{L}$ in fully-adjusted model, 1.08; 95\% CI, 0.95-1.22; $\mathrm{P}=0.26$; annual rate of HR decline, $1.2 \% ; 95 \% \mathrm{CI},-1.2$ to $3.6 \% ; \mathrm{P}=0.32$ ). When only cases with preserved ejection fraction were considered $(\mathrm{n}=136)$, albumin was associated with incident $\mathrm{HF}$ both in univariate (HR per $-1 \mathrm{~g} / \mathrm{L}, 1.15 ; 95 \% \mathrm{CI}, 1.03-1.27$; $\mathrm{P}=0.010$; annual rate of $\mathrm{HR}$ decline, $2.0 \%$; $95 \% \mathrm{CI}, 0.1$ to $3.9 \%$; $\mathrm{P}=0.037$ ) and in multivariate (HR per $-1 \mathrm{~g} / \mathrm{L}$ in fully-adjusted model, 1.12; 95\% CI, 1.00-1.24; $\mathrm{P}=0.041$; annual rate of HR decline, $1.4 \% ; 95 \% \mathrm{CI},-0.5$ to $3.2 \% ; \mathrm{P}=0.16)$ models. However, the difference in the albumin coefficients for HF with impaired vs. preserved ejection fraction did not reach statistical significance $(\mathrm{P}$ value for the $z$ test was $>0.4$ and $>0.6$ for the univariate and multivariate models, respectively).

\section{DISCUSSION}

In this elderly cohort, baseline serum albumin concentration was inversely associated with risk for incident $\mathrm{HF}$ in a time-dependent fashion. This relationship persisted after controlling for other known predictors of HF, several inflammatory biomarkers, and incident coronary heart disease, and was not affected when death was analyzed as a competing risk.

Interestingly, the average baseline serum albumin in participants who developed HF during the entire 10-year follow-up period was not significantly lower compared to those who did not develop HF. This is related to the fact that most participants who develop HF earlier 
during follow-up had lower albumin concentration than later cases. The difference in baseline serum albumin concentrations between those who did and did not develop HF decreased over time, as did the hazard of developing HF with low serum albumin at baseline. Since we did not have serial albumin measurements in the Health ABC cohort, we do not know whether individuals who presented with HF in the long term had developed lower albumin concentrations in the interim. Considering that changes in serum albumin over time have been previously associated with incident cardiovascular risk,5, 17 this is a possibility. Another explanation is regression dilution (or attenuation) bias, ${ }^{18}$ i.e. weakening of the association for those events that occur at remote follow-up periods, as baseline measurements may not be representative of the "true" underlying value of the variable of interest any more. Future studies evaluating serial changes in albumin and risk for incident HF are necessary to completely address these questions.

There are several reasons to believe that serum albumin most likely represents a risk marker and not a risk factor. Hypoalbuminemia has been attributed to a variety of factors, including exogenous albumin loss, albumin distribution, catabolism rate of proteins, and the presence of inflammatory cytokines. Serum albumin concentrations are associated with increased inflammatory burden in the body. Inflammation has been associated with decreasing albumin synthesis rate and increasing catabolism. ${ }^{11}$ In turn, the inflammatory markers studied in this investigation are elevated in patients with HF and asymptomatic left ventricular systolic and diastolic dysfunction, ${ }^{19-23}$ and experimental studies have suggested that IL- 6 and TNF- $\alpha$ are associated with left ventricular remodeling, fetal gene expression, myocyte hypertrophy, and myocyte apoptosis. ${ }^{24}$ For these reasons, serum albumin may be considered as a surrogate marker of inflammatory status. However, controlling for inflammatory markers in our study had no effect on the association between serum albumin concentration and incident HF risk, suggesting that inflammatory status alone does not explain the albumin-HF link entirely.

Another alternative explanation is that comorbidities associated with development of HF are also associated with worsening serum albumin profile. However, our group has carefully assessed clinical predictors of incident HF in the Health ABC cohort in a previous study, ${ }^{7}$ and controlling for all such predictors did not change the association. These observations suggest an interesting role for serum albumin as a strong surrogate marker for incident HF in the elderly, a marker that possibly integrates both known and unexplored pathways. Further insight into anti-thrombotic or anti-oxidant mechanisms, oxidative stress due to the nitric oxide reservoir capabilities of albumin, or other mechanisms may impact future therapeutic interventions.

Interestingly, in our study, low albumin levels appeared to have a strong association with HF with preserved ejection fraction. This is possible, as low albumin is associated with inflammation that has been linked with diastolic dysfunction in animals and humans, ${ }^{25}, 26$ and inhibition of inflammatory pathways improves cardiac function in experimental diabetic cardiomyopathy. ${ }^{27,}{ }^{28}$ Similarly, previous studies have shown a relation between albumin and several comorbidities that are more common among patients with HF with preserved ejection fraction. However, cautious interpretation is needed because post-HF left ventricular function was not assessed systematically in Health $\mathrm{ABC}$ and theses findings are therefore subject to selection bias.

What are the implications of these findings? Considering that the association between serum albumin and incident HF was independent of other risk predictors and consistent in both sexes and in whites and blacks, serum albumin may be useful for HF risk determination among the elderly. For example, the recently published Health ABC Heart Failure Model, ${ }^{7}$ a 
clinical model for HF risk assessment in the general elderly population, can be used to further risk stratify individuals with low serum albumin levels.

Our study has several limitations. Because some participants may have developed HF without requiring hospitalization, HF rates in our study are likely underestimated. Echocardiography was not performed at baseline in the Health ABC Study and left ventricular function during hospitalization for HF was not prospectively assessed either. Because our cohort included elderly only, these findings might not apply in younger populations. Finally, only baseline albumin was available; serial measurements likely would have provided additional information on the mechanisms underlying this association.

In conclusion, in this study we demonstrate that baseline serum albumin concentrations independently predict risk for incident $\mathrm{HF}$ among older adults in a time-dependent fashion. This association appears to be consistent across demographic subgroups, and may be stronger for individuals with HF with preserved ejection fraction. Further studies are needed to delineate the screening potential of serum albumin for high-risk individuals, clinical utility, and other applications based on the findings in this study.

\section{REFERENCES}

1. Gillum RF, Makuc DM. Serum albumin, coronary heart disease, and death. Am Heart J 1992;123:507-513. [PubMed: 1736588]

2. Klonoff-Cohen H, Barrett-Connor EL, Edelstein SL. Albumin levels as a predictor of mortality in the healthy elderly. J Clin Epidemiol 1992;45:207-212. [PubMed: 1569417]

3. Kuller LH, Eichner JE, Orchard TJ, et al. The relation between serum albumin levels and risk of coronary heart disease in the Multiple Risk Factor Intervention Trial. Am J Epidemiol 1991;134:1266-1277. [PubMed: 1755441]

4. Phillips A, Shaper AG, Whincup PH. Association between serum albumin and mortality from cardiovascular disease, cancer, and other causes. Lancet 1989;2:1434-1436. [PubMed: 2574367]

5. Schalk BW, Visser M, Bremmer MA, et al. Change of serum albumin and risk of cardiovascular disease and all-cause mortality: Longitudinal Aging Study Amsterdam. Am J Epidemiol 2006;164:969-977. [PubMed: 16980573]

6. Horwich TB, Kalantar-Zadeh K, MacLellan RW, et al. Albumin levels predict survival in patients with systolic heart failure. Am Heart J 2008;155:883-889. [PubMed: 18440336]

7. Butler J, Kalogeropoulos A, Georgiopoulou Vasiliki, Belue R, Rodondi N, Garcia M, Bauer DC, Satterfield S, Smith AL, Vaccarino V, Newman AB, Harris TB, Wilson PWF, Kritchevsky SB. for the Health ABC Study. Incident Heart Failure Prediction in the Elderly: The Health ABC Heart Failure Score. Circ Heart Failure 2008;1:125-133.

8. Baumgartner RN, Koehler KM, Romero L, et al. Serum albumin is associated with skeletal muscle in elderly men and women. Am J Clin Nutr 1996;64:552-558. [PubMed: 8839499]

9. Rao M, Guo D, Perianayagam MC, et al. Plasma interleukin-6 predicts cardiovascular mortality in hemodialysis patients. Am J Kidney Dis 2005;45:324-333. [PubMed: 15685511]

10. Yeun JY, Levine RA, Mantadilok V, et al. C-Reactive protein predicts all-cause and cardiovascular mortality in hemodialysis patients. Am J Kidney Dis 2000;35:469-476. [PubMed: 10692273]

11. Don BR, Kaysen G. Serum albumin: relationship to inflammation and nutrition. Semin Dial 2004;17:432-437. [PubMed: 15660573]

12. Cesari M, Penninx BW, Newman AB, et al. Inflammatory markers and onset of cardiovascular events: results from the Health ABC study. Circulation 2003;108:2317-2322. [PubMed: 14568895]

13. Fried LP, Borhani NO, Enright P, et al. The Cardiovascular Health Study: design and rationale. Ann Epidemiol 1991;1:263-276. [PubMed: 1669507]

14. Rodondi N, Newman AB, Vittinghoff E, et al. Subclinical hypothyroidism and the risk of heart failure, other cardiovascular events, and death. Arch Intern Med 2005;165:2460-2466. [PubMed: 16314541] 
15. Sauerbrei W, Royston $P$, Binder H. Selection of important variables and determination of functional form for continuous predictors in multivariable model building. Stat Med 2007;26:5512-5528. [PubMed: 18058845]

16. Fine JP, Gray RJ. A Proportional Hazards Model for the Subdistribution of a Competing Risk. Journal of the American Statistical Association 1999;94:496-509.

17. Foley RN, Parfrey PS, Harnett JD, et al. Hypoalbuminemia, cardiac morbidity, and mortality in end-stage renal disease. J Am Soc Nephrol 1996;7:728-736. [PubMed: 8738808]

18. Clarke R, Shipley M, Lewington S, et al. Underestimation of risk associations due to regression dilution in long-term follow-up of prospective studies. Am J Epidemiol 1999;150:341-353. [PubMed: 10453810]

19. Torre-Amione G, Kapadia S, Benedict C, et al. Proinflammatory cytokine levels in patients with depressed left ventricular ejection fraction: a report from the Studies of Left Ventricular Dysfunction (SOLVD). J Am Coll Cardiol 1996;27:1201-1206. [PubMed: 8609343]

20. Tsutamoto T, Hisanaga T, Wada A, et al. Interleukin-6 spillover in the peripheral circulation increases with the severity of heart failure, and the high plasma level of interleukin- 6 is an important prognostic predictor in patients with congestive heart failure. J Am Coll Cardiol 1998;31:391-398. [PubMed: 9462584]

21. Levine B, Kalman J, Mayer L, et al. Elevated circulating levels of tumor necrosis factor in severe chronic heart failure. N Engl J Med 1990;323:236-241. [PubMed: 2195340]

22. Raymond RJ, Dehmer GJ, Theoharides TC, et al. Elevated interleukin-6 levels in patients with asymptomatic left ventricular systolic dysfunction. Am Heart J 2001;141:435-438. [PubMed: 11231442]

23. Williams ES, Shah SJ, Ali S, et al. C-reactive protein, diastolic dysfunction, and risk of heart failure in patients with coronary disease: Heart and Soul Study. Eur J Heart Fail 2008;10:63-69. [PubMed: 18160340]

24. El-Menyar AA. Cytokines and myocardial dysfunction: state of the art. J Card Fail 2008;14:61-74. [PubMed: 18226775]

25. Kuwahara F, Kai H, Tokuda K, et al. Hypertensive myocardial fibrosis and diastolic dysfunction: another model of inflammation? Hypertension 2004;43:739-745. [PubMed: 14967845]

26. Bahrami H, Bluemke DA, Kronmal R, et al. Novel metabolic risk factors for incident heart failure and their relationship with obesity: the MESA (Multi-Ethnic Study of Atherosclerosis) study. J Am Coll Cardiol 2008;51:1775-1783. [PubMed: 18452784]

27. Westermann D, Van Linthout S, Dhayat S, et al. Tumor necrosis factor-alpha antagonism protects from myocardial inflammation and fibrosis in experimental diabetic cardiomyopathy. Basic Res Cardiol 2007;102:500-507. [PubMed: 17909696]

28. Van Linthout S, Riad A, Dhayat N, et al. Anti-inflammatory effects of atorvastatin improve left ventricular function in experimental diabetic cardiomyopathy. Diabetologia 2007;50:1977-1986. [PubMed: 17589825] 

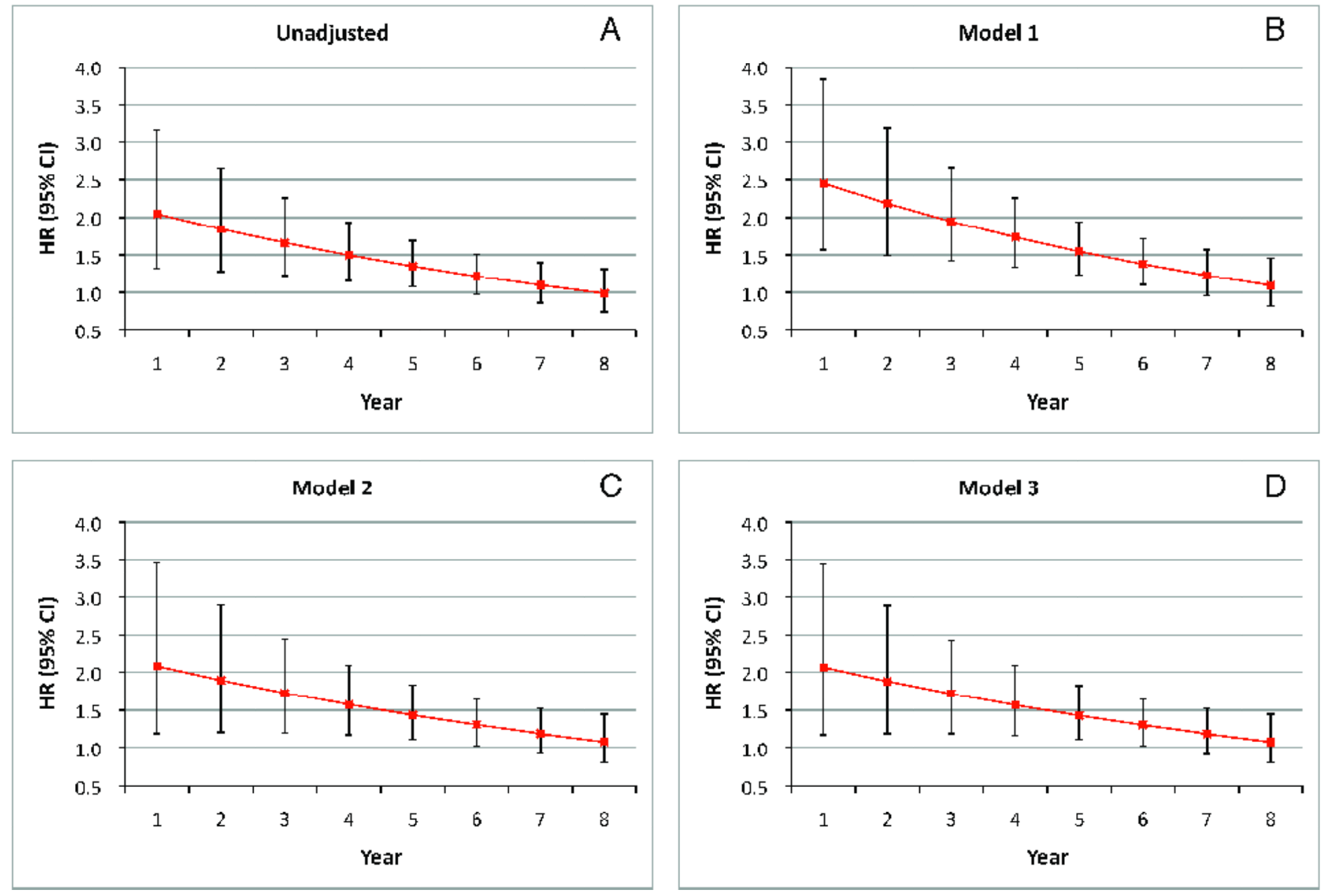

Figure 1. Serum Albumin and Incident Heart Failure Risk Over Time

Hazard ratio over time for incident heart failure in participants with albumin concentrations $<40 \mathrm{~g} / \mathrm{L}$ (participants with albumin concentrations $\geq 40 \mathrm{~g} / \mathrm{L}$ are the reference group). (A) Unadjusted model. (B) Model including clinical predictors of incident heart failure. (C) Model additionally including inflammatory markers. (D) Model additionally including incident coronary events as a time-varying covariate. 


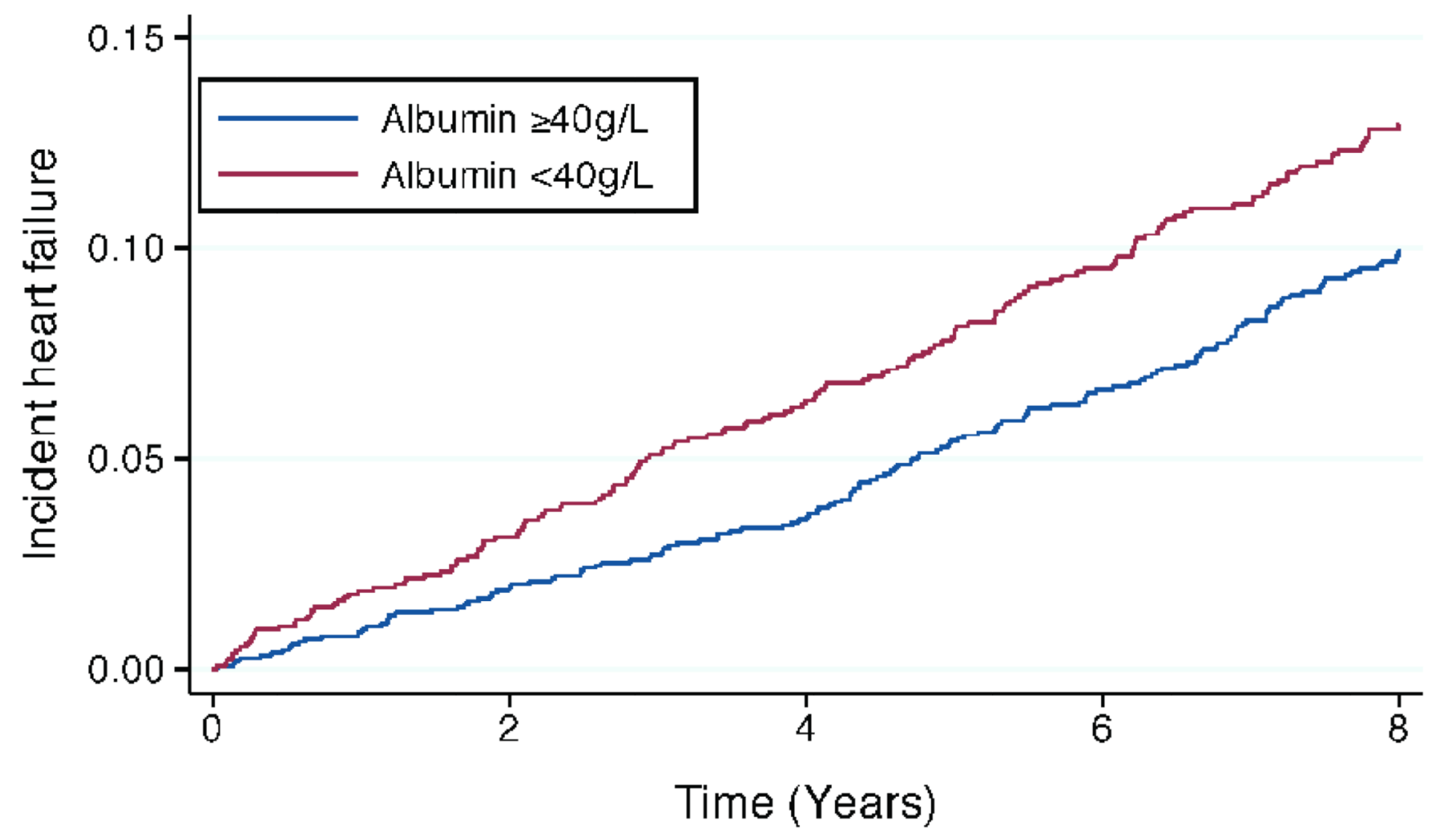

Figure 2. Serum Albumin and Rates of Incident Heart Failure

Kaplan-Meier rates of incident heart failure among participants with baseline albumin concentrations $<40 \mathrm{~g} / \mathrm{L}$ vs. $\geq 40 \mathrm{~g} / \mathrm{L}$ (cohort median). 
Table 1

Baseline Participant Characteristics

\begin{tabular}{|c|c|c|c|c|}
\hline Characteristic & $\begin{array}{c}\text { Overall } \\
(\mathbf{N}=2907)\end{array}$ & $\begin{array}{l}\text { Heart failure } \\
\quad(\mathbf{N}=342)\end{array}$ & $\begin{array}{c}\text { No heart } \\
\text { failure } \\
\text { (N = 2565) }\end{array}$ & $\begin{array}{c}P \\
\text { Value }\end{array}$ \\
\hline Age, years & $73.6(2.9)$ & $74.2(2.9)$ & $73.5(2.9)$ & $<0.001$ \\
\hline Female, $\mathbf{N}(\%)$ & $1513(52.0)$ & $156(45.6)$ & $1357(52.9)$ & 0.010 \\
\hline Black race, $\mathrm{N}(\%)$ & $1201(41.3)$ & $163(47.4)$ & $1038(40.5)$ & 0.015 \\
\hline \multicolumn{5}{|l|}{ Smoking status, $\mathbf{N}(\%)$} \\
\hline Current & $305(10.5)$ & $51(15.0)$ & $254(9.9)$ & $<0.001$ \\
\hline Past & $1311(45.2)$ & $167(49.0)$ & $1144(44.7)$ & \\
\hline \multicolumn{5}{|l|}{ Body mass index, $\mathrm{kg} / \mathrm{m}^{2}, \mathrm{~N}(\%)$} \\
\hline$<25$ & 947 (32.6) & $107(31.3)$ & $840(32.8)$ & 0.001 \\
\hline $25-30$ & $1222(42.0)$ & $121(35.4)$ & $1101(42.9)$ & \\
\hline$>30$ & $738(25.4)$ & $114(33.3)$ & $624(24.3)$ & \\
\hline Systolic blood pressure, mm Hg & $136.0(21.0)$ & $142.8(23.3)$ & $135.1(20.5)$ & $<0.001$ \\
\hline Diastolic blood pressure, $\mathrm{mm} \mathrm{Hg}$ & $71.4(11.7)$ & $72.9(12.9)$ & $71.2(11.5)$ & 0.061 \\
\hline Heart rate, beats per min & $65.3(11.0)$ & $67.4(12.3)$ & $65.0(10.8)$ & 0.002 \\
\hline Hypertension, N (\%) & $1257(43.5)$ & $188(55.1)$ & $1069(42.0)$ & $<0.001$ \\
\hline Diabetes, $N(\%)$ & $424(14.7)$ & $72(21.1)$ & $352(13.8)$ & $<0.001$ \\
\hline Depression, N (\%) & $60(2.1)$ & $7(2.1)$ & $53(2.1)$ & 0.576 \\
\hline Cerebrovascular disease, $\mathrm{N}(\%)$ & $197(6.8)$ & $33(9.9)$ & $164(6.5)$ & $<0.001$ \\
\hline Coronary heart disease, $\mathrm{N}(\%)$ & $472(16.5)$ & $111(33.0)$ & $361(14.3)$ & $<0.001$ \\
\hline Left ventricular hypertrophy, $N(\%)$ & $346(11.9)$ & $56(16.4)$ & $290(11.3)$ & 0.006 \\
\hline Fasting glucose, $\mathrm{mg} / \mathrm{dL}$ & $104.0(34.2)$ & $112.3(45.0)$ & $102.9(32.3)$ & $<0.001$ \\
\hline Albumin, $\mathrm{g} / \mathrm{L}$ & $39.8(3.1)$ & $39.6(3.1)$ & $39.8(3.1)$ & 0.216 \\
\hline Creatinine, $\mathrm{mg} / \mathrm{dL}$ & $1.05(0.4)$ & $1.15(0.5)$ & $1.0(0.4)$ & $<0.001$ \\
\hline Total cholesterol, mg/dL & $203.2(38.3)$ & $199.4(39.3)$ & $203.7(38.1)$ & 0.052 \\
\hline High density lipoprotein, mg/dL & $54.3(17.0)$ & $52.0(17.1)$ & $54.6(17.0)$ & 0.001 \\
\hline Low density lipoprotein, $\mathrm{mg} / \mathrm{dL}$ & $121.9(34.6)$ & $120.0(34.8)$ & $122.2(34.5)$ & 0.190 \\
\hline Triglycerides, $\mathbf{m g} / \mathrm{dL}$ & $136.9(77.0)$ & $137.3(71.9)$ & $136.8(77.7)$ & 0.575 \\
\hline Interleukin-6, pg/mL & $2.4(1.9)$ & $2.9(2.1)$ & $2.3(1.8)$ & $<0.001$ \\
\hline C-reactive protein, $\mu \mathrm{g} / \mathrm{mL}$ & $3.0(4.7)$ & $3.8(6.5)$ & $2.9(4.7)$ & $<0.001$ \\
\hline Tumor necrosis factor $\alpha, \mathrm{pg} / \mathrm{mL}$ & $3.4(1.7)$ & $3.9(1.9)$ & $3.4(1.7)$ & $<0.001$ \\
\hline
\end{tabular}


Table 2

Baseline Serum Albumin Concentration and Risk for Incident Heart Failure

\begin{tabular}{|c|c|c|c|c|}
\hline \multirow[b]{2}{*}{ Model } & \multicolumn{2}{|c|}{ Standard Cox Model } & \multicolumn{2}{|c|}{ Competing Risks Model } \\
\hline & $\mathrm{HR}^{*}(95 \% \mathrm{CI})$ & $P$ value & $\operatorname{SHR}^{*}(95 \% \mathrm{CI})$ & $P$ value \\
\hline \multicolumn{5}{|l|}{ Unadjusted } \\
\hline Baseline HR & $1.14(1.06-1.22)$ & $<0.001$ & $1.13(1.06-1.22)$ & 0.001 \\
\hline Annual decline factor & $0.979(0.967-0.992)$ & 0.001 & $0.979(0.967-0.991)$ & 0.001 \\
\hline \multicolumn{5}{|c|}{ Model 1: Other clinical predictors of incident heart failure ${ }^{\dagger}$} \\
\hline Baseline HR & $1.17(1.09-1.25)$ & $<0.001$ & $1.16(1.08-1.24)$ & $<0.001$ \\
\hline Annual decline factor & $0.979(0.967-0.992)$ & 0.001 & $0.979(0.968-0.990)$ & $<0.001$ \\
\hline \multicolumn{5}{|c|}{ Model 2: Model 1 plus inflammatory markers } \\
\hline Baseline HR & $1.13(1.06-1.22)$ & 0.001 & $1.13(1.05-1.21)$ & 0.001 \\
\hline Annual decline factor & $0.982(0.969-0.995)$ & 0.007 & $0.981(0.969-0.993)$ & 0.002 \\
\hline \multicolumn{5}{|c|}{ Model 3: Model 2 plus incident coronary heart disease ${ }^{\S}$} \\
\hline Baseline HR & $1.13(1.05-1.22)$ & 0.001 & $1.13(1.05-1.21)$ & 0.001 \\
\hline Annual decline factor & $0.982(0.970-0.995)$ & 0.008 & $0.981(0.969-0.993)$ & 0.002 \\
\hline
\end{tabular}

* Expressed per $-1 \mathrm{~g} / \mathrm{L}$ of baseline serum albumin concentration. Competing risks model refers to the Fine and Grey extension of the Cox model with death as a competing event.

${ }^{\dagger}$ Age, Age, history of coronary heart disease, systolic blood pressure, history of smoking, creatinine, heart rate, fasting glucose, and left ventricular hypertrophy

${ }^{*}$ Inflammatory markers include interleukin-6, C-reactive protein, and tumor necrosis factor- $\alpha$

$\S_{\text {Incident coronary heart disease defined as incident myocardial infarction, angina, or coronary revascularization (percutaneous or surgical) }}$

HR: Hazard ratio; SHR: Subhazard ratio 
